\title{
"Remembering Well": Sexual Practice as a Practice of Remembering ${ }^{1}$
}

\author{
KATE BRIDE
}

||

Kate Bride is a provisional doctoral candidate in the Faculty of Education at Memorial University of Newfoundland, St. John's.

If catastrophe is not representable according to the narrative explanation which would 'make sense' of history, then making sense of ourselves and charting the future are not impossible. But we are, as it were, marked for life, and that mark is insuperable, irrecoverable. It becomes the condition by which life is risked, by which the question of whether one can move, and with whom, and in what way is framed and incited by the irreversibility of loss itself.

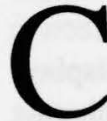

awthra Park, located in the heart of the Church-Wellesley neighborhood of Toronto, is occupied by local adults, children, homeless people, gays and lesbians, dog walkers, sunbathers and mourners. It is also the home to the Toronto AIDS Memorial. An expandable monument of names, ${ }^{2}$ this memorial was constructed in remembrance of those who have died of AIDS in the Toronto area (Silversides 2003), and, by night, has become a venue for gay public sex. The multitude of activities that take place in this park raises questions about space, the function of memorial sites, and the work of remembrance. For, the co-existence of the AIDS Memorial and public sex suggests that the memorial has become a

${ }^{1}$ Many thanks to Ursula Kelly, Jen Gilbert, and Sharon Rosenberg for their insights and suggestions towards this paper.

2 Since 1996 the AIDS Memorial Committee has been adding names to the memorial plaques of those who died in the previous year. 
space in which people are mired in the larger dialectics of life and death, pleasure and suffering, health and moral regulation, sex and illness. $^{3}$

While any relationship between public sex and memorial practices is normatively constructed as contradictory, I will suggest here that public gay sex (particularly when the encounter occurs in the vicinity of an AIDS Memorial) may be understood as a practice of remembering those who have died of AIDS. To think about remembering as contested, as multiple, as complex, we can think about life and death alongside each other. Rather than regarding the AIDS Memorial as a structure that does our remembering for us (as will be discussed later in this paper), perhaps it would be more instructive to think about the memorial as a site of the work of memory, that the memorial incites memory, and makes possible new practices of remembering (including, one could argue, sex).

Key questions arise when thinking about public sex and remembrance: What is, might be and should be the memory of AIDS? What is at stake in remembering AIDS, for those who have died and for those who are still living? The controversy over public sex around the Toronto AIDS Memorial puts into relief the tremendous affective weight of such questions. In fights over the "appropriate" displays of remembrance, we might also ask, what is the work of remembering the losses of AIDS? By way of exploring these questions, I begin by offering some of the texture of the debate concerning the policing of public sex in Cawthra Park, elaborate an analysis of the relations between queer space, Toronto's gay village, and the Toronto AIDS Memorial, and end with an exploration of sexual practice as a practice of remembering. By exploring what is at stake in the relationship between identities, sexual practice, issues of space, and loss, there are countless possibilities for grappling with new forms of remembering that consider the deep complexities of loss in our time.

${ }^{3}$ Such dialectics have played out, in part, through public debates. For example, I sat in on several community meetings in 1996 where there were strong feelings on both sides of the public sex debate. The debate-to ignore the practice of public sex behind the AIDS Memorial or to try and put an end to it-was set as an either/or binary, leaving little room to consider the complexities of the relationship between public sex and memorialization. 


\section{The Toronto AIDS Memorial: The Texture of the Debate}

During the early to mid-1990s the debates surrounding gay public sex ${ }^{4}$ in Cawthra Park seemed to mostly take place in community meetings, between people on the street, at social events. The most recent debates to evolve over what are "acceptable" kinds of behavior in Cawthra Park are many, and branch out from Cawthra Park and the Toronto AIDS Memorial to other known cruising spots within the city of Toronto. The spring and summer of 1999 was a particularly turbulent year for debates over the appropriate use of Cawthra Park, after a two million dollar Community Action Policing (CAP) initiative had police in the Toronto area monitor the kinds of behaviors taking place in parks. The CAP initiative, its aim to reduce crime in green spaces, and to enforce a so-called "anti-sex crackdown," "identified a number of parks all over the city that require[d] some intensive cleaning-also some parks where very clear inappropriate activities were taking place" (Smith 1). Nancy Smith, urban safety consultant and head of an audit that took place in Cawthra Park before the CAP initiative began, said: "Look, this activity is going on in the park-people having sex in bushes, people doing drugs" (in Smith 2). The goal, she says, was to "physically clean it up, and clean it up in terms of having appropriate activity" (in Smith 2). The "clean up" would mean cutting down trees and shrubbery behind the AIDS Memorial and installing spotlights. In this regard, acts of public sex and drug use might be seen as urban design problems where the removal of foliage and shedding more light on the situation would presumably "cure" "inappropriate" behavior. $^{5}$

${ }^{4}$ I realize that the notion of public sex is in itself not unproblematic. As David Bell points out, "In terms of the location of the sex act... it is taking place in public space: the park, the public toilet,... But in terms of the identities of the participants, their knowledge of each other, and the wider 'public' knowledge of the activities that go on in a private setting, public (homo)sex can be very private, only attracting attention... when the police or queerbashers target a particular site for their own kinds of nocturnal activities" (306).

${ }^{5}$ On the evening before the CAP initiative was to begin, former Toronto Mayor Mel Lastman "revealed that it [the CAP initiative] wouldn't take so much as a nip out of violent crime" (in Smith 5). However, Lastman argued "it should be a criminal offence to dispose of a used condom in a city park" (5). The public discourse on a "clean-up" of city parks took hold-in a moment, Lastman's comments criminalized the unspoken world of homosexual activity, public sex. Cawthra Park, a venue for sexual practice, was thus also regarded as a venue for restraint and control. 
The policing of so-called "inappropriate behaviors" is not specific to Cawthra Park. As Eleanor Brown suggests, "Police have always harassed cruisers, at High Park, Cherry Beach, in Cawthra Square Park, and elsewhere" (3). Writing in Toronto's Xtra! at the time, Tyrone Newhook also reported that those caught engaged in sexual activity at a popular nude beach on Toronto Island were being arrested. This was so, even though, "For years, the secluded strip of sand and shrubbery on Toronto Island has been popular among gay men and lesbians. It was the site for Toronto's first gay Pride picnic in 1971 " (1). Lieshout provides a broader framing here, suggesting that 'Impersonal,' 'casual' or 'anonymous' sexual contacts had and still have a bad reputation among the majority of people. It is the kind of sex that violates notions of romantic love, steady relationships or longterm commitment, ideas which are widespread in our culture... That this kind of sex is pursued and enjoyed as an end in itself seems shocking... Public (homo)sexual encounters are contrary to conventional morality and (therefore) to legal rules. (in Bell 307)

The relationship between (public) gay sexual activity and "appropriate" public behaviors in city parks (and other public sites) is a difficult one to say the least, infused as it is with perceptions of normativity, deviance and criminality. Read through the lens of moral regulation, those engaged in "public" sexual practice are seen as partaking in a seedy underworld far removed, in fact entirely separated from, normative notions of private and public behaviors. What is glossed here is how such sexual practices might be inextricably linked to notions of counter-normative and queer sexual identities, sexual communities and sexual politics (Bell 306). Hence, policing continues and heteronormative principles reign.

Although Cawthra Park was one of the many sites of the CAP initiative, city officials felt the park demanded its own special focus. After complaints from local residents that Cawthra Park was attracting too many "undesirables" (cruisers, teens, homeless people, drug users and prostitutes), police ordered a two-hour safety audit of the park. In two hours city officials were to determine, based on the complaints of a few, how to "deal" with the problems of public sex, prostitution, and drug use in the park. People whose residences face the north side of the park constituted the majority of the complainants cited in the safety audit. Eleanor Brown summarizes 
some possible resolutions offered by local residents for pushing out the "undesirables":

They include cutting back some of the lovely thickets by the AIDS Memorial. The comfy window sills along the north wall should be embedded with sharp nails. Or at least blessed with decorative barriers... everything should be flat; trees should be skinny, with all the lower branches cut off, so as not to obscure the line of sight... Residents say they can't sunbathe because of the scary types hanging around the fountain. (2)

Some public perceptions about life in the park are clearly foregrounded by notions of what is acceptable behavior in public (definitely not sexual behavior), and extend notions of private space. Jonathan Dollimore offers some explanation here, reminding us of Foucault's assertion that in the modern period sex became definitive of the truth of our being (222). As he explains, "As such, sexuality in its normative forms constitutes a 'truth' connecting inextricably with other truths and norms not explicitly sexual" (222). This is one of the reasons why, according to Dollimore, sexual deviance is found threatening: "in deviating from normative truth and the 'nature' which underpins it, such deviance shifts and confuses the norms of truth and being throughout culture" (222).

Queers have been prodding at such expressions of normalcy for a long time, making meaning out of difference, finding new ways to live meaningful lives in the face of an ever-powerful heteronormative state. Brown reminds us, "gay men cruising create safety. Prostitutes at every corner mean there's women watching. Kids sneaking a drink aren't your enemy. The homeless are not stalkers" (Sept 23, 1999 3). Moreover, as Bell suggests,

public forms of sex actually involve a redefinition of privacy... The freedom not to have to be 'out,' not to have to subscribe to any identity or community, marks the cruising ground as the very site of this redefinition; the site of 'insecure privacy and selective publicity' for those who cruise it and use it, with 'private sex' taking place in 'public space.' (308)

Public sex (specifically gay public sex) and other expressions of queer life might be seen as powerful signs marking a continued queer rethinking, in this case, of sexual practice, in an effort to disrupt 
heteronormativity and, as already suggested, to make meaning out of difference. Thus, the CAP initiative-to "clean up" inappropriate behaviors, to force out "undesirables"-is just one of the ways that discourses about public space not only regulate particular behavior, but also, work to "erase differences and to limit the forms of expression we have available to us" (Adams 230). ${ }^{6}$ Working against such practices of regulation and dismissal of people's lives, I want to turn now to a more focused exploration of what is at stake in the relations between queerness, community, and space. ${ }^{7}$

\section{Queer(ed) Space: Toronto's Gay Village and The Toronto AIDS Memorial}

From developing blueprints to building parks, memorial sites, and other kinds of public spaces, planners, artists, and others think specifically about the ways that visitors will use these spaces. From relaxation and picnicking to quiet remembering, public spaces are constructed as meant for some behaviors and not others.

The debates over the "appropriate" use of Cawthra Park are a prime example, asking us to look at the ways notions of morality and sexuality make meaning out of local geographies (Adams 218). In their book on queer space, Place and the Politics of Identity (1993), Michael Keith and Steve Pile suggest that it is important to acknowledge that space can be queered or unqueered, depending on the activities and identities expressed at any particular moment. The authors suggest and reinforce, time and time again, the idea that space is fluid and that "we" cannot count on leaving a space only to find it secure upon our return. In other words, we must not be surprised to find that the park we played soccer in yesterday is host to various other kinds of activities, including encounters of a sexual kind, today.

${ }^{6}$ Of all the debates I encountered in my research, none was harder to read than that of the story of Jearld Moldenhauer. In the late summer of 2003 Moldenhauer discovered that the memorial birch tree that he had planted in Cawthra Park for the late James McPhee had been removed by a city worker (in Smith 3). Moldenhauer saw an anti-sex crackdown that went beyond the confines of Cawthra Park. Having recently visited High Park, another known and well cruised spot for gays, Moldenhauer said: "Enormous areas of large trees have suddenly disappeared - clear-cut... I don't think this has anything to do with safety" (3).

${ }^{7}$ Saying this, I keep at the fore that there is no such thing as a coherent queer self, and that being queer is definitely not a unitary experience. 
As Adams asserts, "Places, in and of themselves, have no meaning. Without human activity and social discourse, a particular park, alleyway, or commercial amusement centre is no more 'immoral,' 'romantic,' or 'sexually charged' than another" (219).

The gay village of Toronto, the context of Cawthra Park and the Toronto AIDS Memorial, is a clearly marked space of queerness, its boundaries extending as far as the symbols of gay iconography travel. No single sign creates this space, but their accumulation, a manifestation of the impulses of many individuals, marks certain streets as queer in this particular neighborhood where signs and flags proclaiming "gay pride" are an integral part of the landscape. Christopher Reed suggests, "queer space is space that is space in the process of, literally, taking place, of claiming territory" (64). In this light, the personal (how people identify in the space), the conceptual (how people think about the space) and the physical (the space itself) are inextricably linked.

The physical / visual markers of Toronto's gay village tend to correspond with other European and North American cities' queer spaces. For instance, common to many of the larger queer communities in cities are storefront displays, which respond to the presence of significant pedestrian traffic. In Toronto, as in other queer neighborhoods, like New York's Greenwich Village and Christopher St., or San Francisco's Castro District, discos and bars line the street and present obvious and distinct queer locations with symbols of queer culture (rainbow flags, pink triangles, "queer positive" graffiti, stickers, banners). Less visible are the equally important student groups, social service and political organizations, clubs, and other non-commercial venues where many of us came to constitute our sexuality on the basis of a certain understanding of "community."

The difficult concept of "community," which in Toronto's gay village ideally embraces those who identify variously as lesbian, gay, bisexual, transsexual and/or transgendered, makes the gay village, in part, a refuge from the prejudices and ignorance of society at large. However, as Iris Young points out, not addressing the idea of "community" with a critical eye is problematic:

The ideal of community privileges unity over difference, immediacy over mediation, sympathy over recognition of the limits of one's understanding of others from their point of view. Community is an understandable dream, expressing 
a desire for selves that are transparent to one another, relationships of mutual identification, social closeness and comfort. The dream is understandable, but politically problematic... because those motivated by it will tend to suppress their differences among themselves or implicitly to exclude from their political group persons with whom they do not identify... moreover, [it] is an unrealistic vision for transformative politics... (in McDowell 128).

Like remembrance, we must encounter notions of community in complex terms as best we can, otherwise we run the risk of other kinds of losses-for example, lost dreams tied to a sense that the members of my community will always want, act, and desire the same ways as I. Like the notion of community, it is important to acknowledge that queer space is contested space; the terms of inclusion and exclusion are the subject of heated and on-going debate, as the controversies surrounding the AIDS Memorial amply illustrate.

However, rather than interpreting this conflict as an indication of how queer communities are fractured, we might also suggest that passionate arguments are necessary to vital neighborhoods and communities. As Lippard suggests, "Like the places that they inhabit, communities are bumpily layered and mixed, exposing hybrid stories that cannot be seen in a linear fashion, aside from those 'preserved' examples which usually stereotype and oversimplify the past" (24). Community, for Lippard, doesn't mean understanding everything about everyone and resolving all the differences; "it means knowing how to work within differences as they change and evolve" (24).

\section{The Village}

Located within Toronto's gay village is the 519 Church St. Community Centre, around which the gay village has developed since the early 80 s. It is seen by many as the political and social heart of the community. Affectionately known as "the 519," the centre is a place where one can go for lunch in the cafe, attend an AA meeting with other queers, go to a gay square dance, take in an art show or a seniors' coming out group, attend a riding association meeting for the Liberal Party, go to a transgendered youth group or a Toronto Girl Guides meeting.

The 519 sits at the curb side of Church Street, holding Cawthra Park to the side and behind. It is as if the 519 holds the space of the 
park in its arms, off the street in safety. Cawthra Park hosts a wide variety of activities, including tai chi classes in the warmer seasons, a day care, sports activities, a no-leash zone for dogs, meeting places and living spaces for homeless people, lunch destinations for local workers, nighttime cruising, and a space to collectively mourn. The park can be seen to be a "renovated space," a space that is continually under construction with all its comings and goings. The facade of windows that line the north edge of Cawthra Park gives one the sense of being in an unfinished living room looking out on the world. To belong, one need only stand on the inside of the windows. While, of course, this metaphorical image is highly utopic, we might also remember that the inside is an illusory construct and not without its own conflicts (residents continually complain that the dogs ruin the landscaping of the park, public sex is fiercely practiced and policed).

The intersections of space and identities that I am touching on here are most clearly articulated in the confluence of queerness and identities in the domain of AIDS work, which has so significantly shaped our sense of the gay community. In their collection of essays titled Mapping Desire, David Bell and Gill Valentine suggest that:

... the emergence of organized political groups of people with AIDS has forced issues of health and illness into a public visibility which threatens traditional assumptions of privacy and public heterosexual privilege. The struggle against the stigmatization of AIDS has forced many gay men and lesbians to reject the relative pleasures of the closet...for a radical insistence on the right to be 'queer' on their own terms in public. (23)

Indeed, this emergence can be seen in Toronto, with AIDS organizations, public health and educational clinics scattered through the village and beyond. The Wellesley Hospital, just a few blocks to the east of Church St. (the main commercial section of the village), for example, was the first medical institution in Toronto to initiate a sensitivity training program that would teach staff how to detect when a patient has been beaten up or bashed as a result of homophobia. Voices of Positive Women, an organization that focuses on women living with HIV/AIDS, is located on Church St., and while it does not exclusively serve the lesbian community, its location in the gay village suggests the intimate connection between AIDS work and gay life. It is this connection between AIDS and the gay community that led to the AIDS memorial being erected in Cawthra Park. 


\section{The Toronto AIDS Memorial}

The first AIDS Memorial, located within the boundaries of the park, was conceived in 1988 by activist and educator Michael Lynch. During a 1987 trip to Washington, DC, to attend The March on Washington, Lynch visited the AIDS Quilt and Vietnam Veterans Memorial; both sites strongly influenced his desire to enact a memorial project in Canada (Silversides 161). "During a Christmas 1987 visit to California, Lynch also had long discussions with gay historian Allan Bérubé, who had made his own video of the AIDS Quilt and encouraged Lynch's efforts to "enact common mourning" (161). In a 1988 article Lynch confirmed his plans to move forward with an AIDS memorial, asking: "Are we ready for communal naming, once and for all, to replace dehumanizing numbers?... An old cliché motivates me a lot these days. It goes: 'That they shall not have died in vain'" (in Silversides 161). Inspired by the Vietnam Veterans Memorial, Lynch advocated for a memorial to make speakable and visible the lives lost and the silence surrounding the disease:

for the thousands of HIV positive persons, anti-AIDS practices in employment, insurance, immigration law and community responses contribute to reinforcing the silence... This context of silence has shaped much of the strategy to fight AIDS. Community AIDS organizations have insisted on Making AIDS speakable and visible. (in Silversides 229)

The AIDS Memorial was erected by Lynch and friends in the early morning of Pride Day 1988. In a magazine article published after the unveiling of the first AIDS Memorial, Lynch's friend Gerald Hannon wrote:

We all joke that it is as tasteful as only a dedicated group of homosexual decorators could make it. Inside, past the great vases of flowers at the entrance, you wander down a quiet hallway of pale greens and blues and mauves, soft earth colours set off by the startling white of support ropes, by evergreens, by the achingly blue sky. Each panel carries a list of names, each name carefully inscribed in silver ink on a small placard. (in Silversides 172)

There were 200 names on the memorial when it was unveiled at noon, and by $7 \mathrm{pm}$ another 100 names had been added (in Silversides 173). In his diary that evening Lynch wrote: “'they filed through slowly, almost single file, with such barely held in emotions... I cried a lot just watching others cry"' (in Silversides 173). 
In 1990 the AIDS Memorial Committee ${ }^{8}$ called a design competition for a "permanent" memorial to be located in Cawthra Park, and in 1991 the design of Toronto-based architect Patrick Fahn was chosen, endorsed by Toronto City Council. ${ }^{9}$ Unveiled in June of 1993, the memorial is comprised of fourteen pillars, each 2.45 metres high. Affixed to each pillar are stainless steel plaques onto which are engraved the names of those who have died of AIDSrelated illness. Beginning in 1996, the AIDS Memorial Committee took action to ensure that suitable space be available for all names. Indeed, this continues to be the case today. As new pillars and plaques are needed, room will be made. The memorial site includes a small growth of mature trees that line the back end of the memorial as it forms a semi circle, the pillars and plaques are often decorated with flowers, notes, and burning candle jars left by loved ones.

\section{Re-Presentations: Sexual Practice as Remembering}

So far I have outlined some of the debate concerning public sex in Cawthra Park and have tried to draw relations between queer(ed) space, Toronto's gay village, and the AIDS Memorial. As I begin this next piece on sexual practice as remembering, the questions of what is the memory of AIDS, what is at stake in remembering AIDS for the living and, what is the work of remembering the losses of AIDS, are central. These questions open the grounds for new ways of thinking about loss and remembrance in relation to the Toronto AIDS Memorial.

In thinking through the difficult relations of loss and remembrance there is a logic that says if we are to move into the future, traumatic history-in this instance, countless losses to AIDS-must

${ }^{8}$ The AIDS Memorial Committee, formed by Lynch in 1988, takes care of spring clean-up, planting flowers around the memorial site, organization of the AIDS Vigil every Thursday before Pride Day, and the yearly addition of new names to the memorial.

${ }^{9}$ Lynch was a major force behind calling a design competition for the construction of a permanent AIDS Memorial in Cawthra Park, suggesting that the Memorial would perform a number of critical functions: "It gives a focus for personal and public grief. It counters the silencing and denial, the isolation and rejection..." (in Silversides 230). Less than two months before his death, Lynch adjudicated the competition for the design of the permanent Toronto AIDS Memorial (in Silversides 234). 
be "dealt" with, put into their place in history. The manifestation of "laying our losses to rest" shows itself, often, in the form of a monument, what Lippard might refer to as a "preserved" story of loss-static, unchanging, cemented. Pierre Nora (1989) notes that the emergence of such memorializing initiatives, in one form or another, "involves settling scores with the past" (4). Perhaps the drive behind such pervasive practice, as Simon, Rosenberg, and Eppert suggest, is that the pedagogical justification of remembering loss promises that if we learn the lessons of history we will avoid repeating the mistakes of the past (2). However, as emergent and differing groups continue to memorialize losses on a national, community, and personal scale, mass violence, discrimination in many forms, wars, and other terrible injustices continue to ravage societies.

In other words, an acknowledgement of past traumas and injustices through particular representations of loss and trauma does not equal a remembrance of the past that offers hope for a different future. Following Simon, Rosenberg, and Eppert, learning the lessons of the past through remembrance practices is hardly enough (2). Rather, they suggest the need to develop "remembrance pedagogies" that entail a (re)enactment of the tellings of traumatic histories (7). In the case of reading the AIDS Memorial, such pedagogies may be understood to

encompass not only (a retelling) of the story of another but also the story of the telling of the story. What this signals is the struggle to work through one's own affiliations with the differences from the "original" narrative or memory one is engaging, a working through that takes into account the particularities of the space/time of one's engagement, the particular investments one brings to remembrance, and the continuities and discontinuities one enacts in relation to it. (7)

What these writers are signaling-especially important for an encounter with the Toronto AIDS Memorial-is the complexity with which every story of loss must be encountered. What might it mean to understand sexual practice as a practice of remembering? How does space matter? Who and what is being remembered when remembrance takes the form of public sex? How does the publicness of the sex matter?

The Toronto AIDS memorial was placed in a space that was known to host gay public sex. This history has not been displaced by 
what some regard as the "sacred" space of the memorial. Indeed, gay men continue to engage in sex under the (literal and metaphorical) threat of HIV infection at this site. As Cindy Patton suggests, "The ways of being within sexual cultures are difficult to articulate, their processes of acculturation-their practices-are to some extent unspeakable, unformalizable" (142). While the moral majority regards cruising as proof of gay men's pathology, I want to argue for the co-existence of public sex and a memorial to public sex (since AIDS is also inextricable from all so-called deviant sexualities) as a sign of hope that, after Patton, is "unformalizable." In a sense, the coexistence of these practices may allow us to reckon with the ways sex has been linked to death and illness without collapsing these terms. It is the co-existence of the memorial and public sex that makes Cawthra Park a contested memorial site, that is, a site that contests the grounds of heteronormative moral regulation.

This understanding of the memorial-as a site of memory, disavowal and resistance - is in contrast to traditional theories of how monuments function. The traditional assumptions regarding memorials and memorial sites are that they remember for us, as Pierre Nora has suggested; that is, they have come to be regarded as "displacements of the memory they were supposed to embody... once we assign monumental form to memory, we have to some degree divested ourselves of the obligation to remember... in shouldering the memory work, monuments may relieve viewers of their memory burden" (in Young 5). Rather than regarding the AIDS memorial as a structure that does our remembering for us, perhaps it would be more instructive to think about the memorial as a site of the work of remembering.

The AIDS memorial was conceptualized as a "permanent"10 monument to those who have died from AIDS—on Lynch's terms, to make visible and speakable lives lost and the social ramifications of HIV/AIDS - and thus works to preserve a remembrance of the dead. However, remembrance in the form of public sex suggests that other kinds of memorialization or commemorative practices run parallel to the more sedimented functions of a memorial site.

${ }^{10}$ Permanent in the sense that the foundational structure sits in the park, but not permanent in the sense that new names are added to the plaques annually, hence the memorial changes every year. 


\section{0 / Bride}

Certainly public sex could account for the improvised and embodied practices that both mark the losses of AIDS and hold onto a feeling of hope for the future-not for the future to be post-AIDS necessarily, but a future that still allows for a freedom of sexual practices. How AIDS loss is faced is a new "difference" (in this case, among the living in relation to the dead) within queer community, a difference that needs to be grappled with and engaged in ways that other differences (e.g. how one understands one's self as embodied in relation to sex/gender/sexuality) have been and continue to be faced. ${ }^{11}$

One complex encounter with a story of loss, one new difference of remembering in light of AIDS, manifests itself in relation to the protests concerning public sex in Cawthra Park. There is a message in sex education that suggests that if gay men stop having public sex in the trees behind the memorial, they will not acquire HIV. In other words, in refraining from public sex, there is some evidence that something has been learned-and that to use the park as a space for public sex is to refuse what has (not) been "learned."12 However, the linearity of this argument suggests that gay desire is a death wish-if you want to live, do not engage in public sex (presumably unprotected sex)-leaving no room for the possibility that public sex may be protected sex. Protection, however, is not the point I am getting at; rather I am interested in the ways public sex is always assumed to be unprotected, that is, always deviant sex. The publicness of public sex does matter and recalls Dollimore's assertion that "such deviance shifts and confuses the norms of truth and being throughout culture" (222). Re-posing the question, what then are the losses to AIDS?, demands that we think about the complexity of sexual practice after AIDS, the ways that public sex is connected to resistance (to heteronormativity), to expressions of pleasure and desire, and multiple losses of an "unformalizable" sexual culture.

Another difference related to the "safer sex" narrative that has developed in Western society over the years calls into question what it means that an HIV-negative man and an HIV-positive man engage in sexual practice (whether anonymously or not). As Walt Odets

11 Thanks to Sharon Rosenberg for this clarity.

12 Thanks to Ursula Kelly for this insight. 
suggests, articulating a difference for some in queer community that has been grappled with to some extent,

To reject HIV-positive gay men as a group, or a particular man because he carries HIV, raises serious psychological conflict in many men. It is a decision that necessarily entails the rejection or denial of positive feelings and identifications with one's community and with innumerable individuals. This fact, obvious to most gay men, is by mainstream American [Western] standards both radical and almost incomprehensible. (166)

The above brings forth the point that particular (normative or "mainstream") ways of thinking about intimacy, sex and AIDS (by no means mutually exclusive) do not work for many queers struggling to live in the shadows of loss. Judith Butler's insight with which I opened the paper is helpful here:

If catastrophe is not representable according to the narrative explanation which would "make sense" of history, then making sense of ourselves and charting the future are not impossible. But we are, as it were, marked for life, and that mark is insuperable, irrecoverable. It becomes the condition by which life is risked, by which the question of whether one can move, and with whom, and in what way are framed and incited by the irreversibility of loss itself. (Butler 472)

After and in the midst of such losses to AIDS, making complex sense of ourselves in queer community is to enact what Simon, Rosenberg and Eppert refer to as the "continuities and discontinuities" that we perform in relation to loss (7), whether taking part in a vigil, visiting the memorial on the anniversary of a friend's death, eating lunch on the steps of the memorial and attending to its presence, or having sex behind/on/in the vicinity of the memorial.

In his article "Melancholia and Moralism," Douglas Crimp suggests that, "If following Foucault, a central tenet of queer theory has been an analysis of, and resistance to, normalizing technologies of power" (201), then, conversely, it is possible to think about some monuments as normalizing technologies of memorialization. That is, when a monument or memorial site (and the actions that surround it) are positioned to stand as representative of only one aspect of a loss, this is normalizing and works to shut out all other kinds of grief related to that loss. 
My relationship to the AIDS memorial in Cawthra Park, so far, is one that is marked by loss of friends and friends of friends who have died due to AIDS; a "community" that continues to struggle with the ravaging effects of HIV/AIDS; a "community" that continues to feel the impact of homophobia on a day-to-day basis. A deeper look into the Toronto AIDS Memorial must have us see that some perceptions of monuments and memorializing practices can and do function as normalizing practices of power that refuse multiple stories, multiple rememberings of loss due to AIDS, and often foreclose complex psychic processes involved with remembering our dead and our experiences of loss and trauma.

\section{Remembering Well}

In facing and coming to terms with loss, Simon, Rosenberg, and Eppert evoke the remarkable notion of "remembering well." "Remembering well" is "a remembering that humbles any design to master the past and requires a serious reflexivity rooted in a recognition that the historical character of one's partial and mediated remembrance is contingent and thus can always be otherwise" (7). Remembrance, they suggest, is "a means for an ethical learning that impels us into a confrontation and 'reckoning' not only with stories of the past but also with 'ourselves' as we 'are' (historically, existentially, ethically) in the present" (8). To remember well is to read with complex frames, to learn to live with loss, to trace who and what stories are made to matter. Remembering well is a way of "dwelling in history that keeps open remembrance as a promise of hope" (Simon 10). As such, remembering well constitutes an ethical practice, an ongoing relationship to the past and the present, offering possibilities for change. The relationship between remembering well and public sex might be seen as a new (re)investment in thinking about life and death alongside each other, unencumbered by "mainstream" narratives that shame and oppress.

Loss changes us, diminishes our lives in significant ways. In the present and growing presence of death due to AIDS all around us, and with no end in sight, remembering well means encountering the dead - whether in the form of a vigil, monument, quilt, or sexthrough our "continuities and discontinuities" with them. Neatly packaging what it means to remember the losses of AIDS into a particular monument or memorial site will continue to lead us to 
not talk about the pain of our losses. Gay men, I am arguing, go cruising, among many other things, as part of what it means to mourn. As Simon Watney suggests, this is the complex nature of queer community, and it is inseparable from the epidemic in its midst (169).

For Michael Lynch, the AIDS Memorial was to offer a focal point for personal and public grief, to work against the silencing, denial, isolation and rejection that so many people living with HIV/ AIDS experience(d) (in Silversides 230). At the core for Lynch was that the AIDS Memorial might also function as a support for the development and existence of what he called a "community of grief." The AIDS Memorial's

identifiable presence contributes directly to the communal awareness that is necessary to lessen the great sufferings ahead for many people... over the next decades, the suffering of the ill and the surviving will be diminished by the AIDS Memorial. In it, a community of grief takes form. The struggle against the silence and suppression gets a focus. (Lynch in Silversides 230)

Lynch's profound sense of a "community of grief" can be seen as an aspect of remembering well and brings back around hope for the future in making visible the relationships and intersections between loss, community, identities, space, and other aspects of the everyday. As Butler points out, "Loss becomes condition and necessity for a certain sense of community, where community does not overcome the loss, where community cannot overcome the loss without losing the very sense of itself as community" (468). A "community of grief" might be seen as a promise of hope, an environment where facing loss becomes a part of our selves, of what it means to live in the world, with our losses.

\section{Conclusion}

Representations of loss that memorial sites try to hold, created out of our shared experience, will go on functioning in much the same way, if allowed to do so. What I hope to have raised here is some of what is at stake in grappling with the question of how works of public art / architecture help us or fail to help us remember. The Toronto AIDS Memorial, read as situated in the dailyness of people's lives, may challenge the normative understandings of remembrance. This reading of the Toronto AIDS Memorial suggests that difficult experiences 
will never go away, that monuments and memorial sites cannot remember for us, and that we are compelled to think about what it means to live with loss on a daily basis (a vital component of remembering well). In this time of AIDS it is urgent for us to ask ourselves what we want to remember and how. Now more than ever, it is incumbent upon us to keep open conversations about the relationship between memorialization and sexuality. New ways of remembering (as public sex) may help us face the challenges that arise, respecting and promoting new ways of remembering, taking notice of the imperative to radically recognize difference and remembering well as a relation between past and present, dead and living.

\section{Works Cited}

Adams, Mary Louise. "Almost Anything Can Happen: A Search for Sexual Discourse in the Urban Spaces of 1940s Toronto.” Studies in Moral Regulation. Ed. Mariana Valverde. Toronto: Centre for Criminology and Canadian Journal of Sociology. 1994. 217255.

Bell, David. "Perverse Dynamics, Sexual Citizenship and the Transformation of Intimacy." Mapping Desire. Eds. David Bell and Gill Valentine. London: Routledge, 1995. 304-317.

Bell, David and Gill Valentine, eds. Mapping Desire. London: Routledge, 1995.

Brown, Eleanor. "Next on the List." Xtra! 26 Aug (1999): 20 pars. 18 July 2004 <www.xtra.ca/site/toronto2/arch/body265.shtm>. Brown, Eleanor. “A Scarey Night in Cawthra.” Xtra! 23 Sept (1999): 21 pars. 18 July $2004<w w w . x t r a . c a / s i t e / t o r o n t o 2 / a r c h /$ body293.shtm>.

Butler, Judith. "Afterword: After Loss, What Then?" Loss. Eds. David L. Eng and David Kazanjian. Berkeley, Los Angeles, London: University of California Press. 2003. 467-474.

Crimp, Douglas. "Melancholia and Moralism." Loss. Eds. David L. Eng and David Kazanjian. Berkeley, Los Angeles, London: University of California Press. 2003. 188-202.

Dollimore, Jonathan. "Post/modern: On the Gay Sensibility, or the Pervert's Revenge on Authenticity." Camp: Queer Aesthetics and the Performing Subject: A Reader. Ed. Fabio Cleto. Ann Arbor: University of Michigan Press, 1999. 221-236. 
Keith, Michael and Steve Pile, eds. Place and the Politics of Identity. London: Routledge, 1993.

Lippard, Lucy. The Lure of the Local: Senses of Place in a Multicentered Society. New York: The New Press, 1997.

McDowell, Linda. "City Life and Difference: Negotiating Diversity." Understanding Cities: Unsettling Cities. Eds. John Allen, Doreen Massey and Michael Pryke. London and New York: Routledge, 1999. 95-136.

Newhook, Tyrone. "No More Sex." Xtra! 22 Apr. (1999): 19 pars. 19 July 2004 <www.xtra.ca/site/toronto2/arch/body 160 .shtm>. Nora, Pierre. "Between Memory and History: Les Lieux de Memoire". Representations 26 (1989): 3-20.

Odets, Walt. In the Shadow of the Epidemic: Being HIV-Negative in the Age of AIDS. Durham, NC: Duke University Press, 1995.

Patton, Cindy. Last Served? London: Taylor and Francis, 1994.

Reed, Christopher. "Imminent Domain: Queer Space in the Built Environment", Art Journal Winter (1996): 64-70.

Silversides, Ann. AIDS Activist: Michael Lynch and the Politics of Community. Toronto: Between the Lines, 2003.

Simon, Roger I. "The Paradoxical Practice of Zakhor: Memories of "What Has Never Been My Fault or My Deed"." Between Hope and Despair: Pedagogy and the Remembrance of Historical Trauma. Eds. Roger I. Simon, Sharon Rosenberg and Claudia Eppert. Lanham and Oxford: Rowman and Littlefield, 2000. 926.

Simon, Roger I., Sharon Rosenberg and Claudia Eppert, eds. Between Hope and Despair: Pedagogy and the Remembrance of Historical Trauma. Lanham and Oxford: Rowman and Littlefield, 2000.

Smith, Vern. “'Fixing' Cawthra Park.” Xtra! 23 Sept. (1999): 42 pars.

18 July 2004 <www.xtra.ca/site/toronto2/arch/body294.shtm>. Young, James E. The Texture of Memory: Holocaust Memorials and Meaning. New Haven and London: Yale University Press, 1993. 